\title{
Normative ultrasound values of renal parenchymal thickness among adults in Enugu, South-East Nigeria.
}

\author{
Eze Charles ${ }^{1}$; Okoye Joy ${ }^{2}$; Agwu Kenneth ${ }^{3}$
}

1. University of Nigeria, Enugu Campus, Medical Radiography and Radiological Sciences

2. Faculty of Medicine, University of Nigeria Teaching Hospital, Ituk-Ozalla, Radiation Medicine

3. Faculty of Health Sciences and Technology, University of Nigeria, Enugu Campus,, Medical Radiography and

Radiological Sciences

\begin{abstract}
Background: Reduction in renal length was found to be an insufficient independent indicator of chronic renal disease.

Objective: To determine the ultrasound normative values of renal parenchymal thickness (RPT) among adults and correlate them with age and somatometric parameters.

Methods: This was a prospective clinic based study involving 310 normal adults (135 males and 175 females) scanned at University of Nigeria Teaching Hospital, Enugu between August 2003 and November 2004. The RPT measurements were made from the outer renal cortical margin to the outer margin of the sinus echoes at the three major poles. The age, height, weight and body mass index were recorded for each subject.

Results: The average RPT are $1.85 \pm 0.20 \mathrm{~cm}$ for the right kidney and $1.95 \pm 0.19 \mathrm{~cm}$ for the left kidney. RPT exhibited strong positive correlation with height, weight and body mass index and significant negative correlation with age. No significant difference in mean RPT of both kidneys between genders ( $p>0.05)$. The mean RPT of the left kidney was found to be statistically higher than that of the right kidney $(\mathrm{p}<0.05)$.
\end{abstract}

Conclusion: Normal values of RPT are important in the evaluation of patients with chronic renal disease.

Keywords: Adult, Kidney, Parenchymal thickness, 1Ultrasound.

DOI: http://dx.doi.org/10.4314/ahs.v14i3.27

\section{Introduction}

Ultrasound is said to be able to identify end stage kidney and give prognostic information ${ }^{1}$. Increased cortical echogenicity correlates poorly with both the presence and type of renal disease ${ }^{2,3,4}$. Reduction in renal length (RL) has been found to be an insufficient independent indicator of chronic renal disease (CRD). This conclusion was drawn because certain patients who were selected for renal biopsy based on RL criterion alone and who were also noted to have a reduction in renal parenchymal thickness (RPT), turned out with a poor prognosis after biopsy ${ }^{5}$. This observation aroused

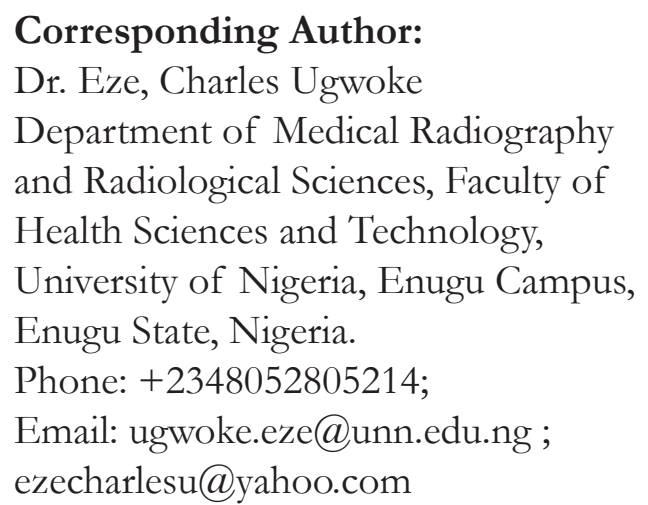

interest on the importance of measuring the RPT before renal biopsy. It was suggested that renal biopsy should not be performed if the RL is less than $9 \mathrm{~cm}$ or RPT is $1 \mathrm{~cm}$ or less ${ }^{6}$. Renal parenchymal thickness was found to be most significantly reduced in patients with $\mathrm{CRD}^{5}$ and to be one of the ultrasonic renal parameters that can offer prognostic information on end stage kidneys ${ }^{1}$. Roger et $\mathrm{al}^{5}$ also reported that there was potential for improvement if the parenchymal thickness was between 1 to $1.5 \mathrm{~cm}$ and that irreversible change was associated with a parenchymal thickness less than $1.0 \mathrm{~cm}$.

Excretory urography ${ }^{7}$, computed tomography ${ }^{8}$, and ultrasound ${ }^{9}$ have been used for the development of normative standards of RPT in children. Both excretory urography and CT techniques use ionizing radiation in contrast to ultrasound which can be performed beside and is readily available. Renal parenchymal thickness can be defined as the distance between the cortex-perirenal fat interface (capsule) and the sinus-pyramidal apex interface of the kidney.

There is scanty published data on sonographic normal values for RPT measurements in adult Caucasian population and none exists so far for any Nigerian population in the literature. Moreover, racial differences 
in renal parameters have been found to exist ${ }^{10}$. This research reports findings on sonographic assessment of RPT in normal adult Nigerians from the Southeast geographical zone.

\section{Subjects and Methods}

The study participants were adult patients aged 18 years and above referred for routine abdominal scan within the period of study in the study centre and who met the selection criteria. Patients with normal serum creatinine, no history of renal or malignant disease, no evidence of renal cyst or abnormal sonographic appearances of the kidneys and subjects in which three RPT measurements were possible to obtain for each kidney at its upper, lower and mid level poles were included. Pregnant females, subjects with abnormal serum creatinine, renal cyst, abnormal renal parenchyma, known diabetic and hypertensive patients as well as patients below 18 years of age were excluded.

Ethical approval was obtained from the University of Nigeria Teaching Hospital Ethical Committee while informed consent was obtained from each subject prior to data collection.

The RPT of 310 subjects who met the inclusion criteria were measured prospectively between August 2003 and November 2004 at the University of Nigeria Teaching Hospital, Enugu using cross sectional research design and convenience sampling method.

All the subjects underwent real time ultrasound scans using a high resolution Medison's Sonoace 3200 (Japan) medical ultrasound machine equipped with a $3.5 \mathrm{MHz}$ curvilinear transducer. The ultrasound machine was validated for quality performance by the departmental medical physicist prior to the measurements. All the sonographic examinations were performed by the same sonographer with 11 years of experience in abdominal sonography when the study began.

Longitudinal scans were performed with the patient in the lateral decubitus position or in supine oblique position ${ }^{5}$. The sonograms that displayed the elliptical kidney outline with central sinus echo complex and the poles were used for the measurement. Thus, RPT at the upper, lower and the mid level poles of the kidneys were measured for each kidney three times after which the mean was recorded ${ }^{5}$. The RPT measurements were made from the outer renal cortical margin to the outer margin of the sinus echoes at each site (figure 1$)^{5}$. Apart from the RPT measurements, age, gender, height, weight, and BMI were also recorded in all the subjects. Anthropometric measurements were obtained on the participants wearing light weight street clothes without shoes. Weight was measured on a calibrated portable Salter scale (BR 9011; Hana Co. Ltd, China) to the nearest $0.1 \mathrm{~kg}$. Height was measured with a metal tape measure to the nearest $0.5 \mathrm{~cm}$ with the participants standing upright with the head in the Frankfurt position ${ }^{11}$. The age of each subject was obtained from his / her hospital birth certificate.

\section{Statistical Analysis}

Results are reported as mean $(\mathrm{X}) \pm$ standard deviation (SD). Descriptive statistic was used in establishing the RPT normogram.

$\mathrm{Z}$ - test statistic was used in comparing: the mean RPT of males and females, and the mean RPT of the study group and that of a Caucasian (UK) and Pakistani populations. A comparison between the left mean RPT and right mean RPT was also done using $\mathrm{Z}$ - test since the population was large and normally distributed and their standard deviations known ${ }^{12}$.

The correlations between RPT and age, height, weight and BMI were performed using Pearson's linear ' $r$ ' test.

Linear regression analysis was used to create models for calculating normative values.

Table 1. RPT Nomogram

\begin{tabular}{|c|c|c|c|c|c|}
\hline Kidney & Subjects & $\%$ & $\begin{array}{l}\text { Mean } \\
(\mathrm{cm})\end{array}$ & $\mathrm{SD}(\mathrm{cm})$ & Range $(\mathrm{cm})$ \\
\hline Right & 310 & 100.0 & 1.85 & 0.20 & $1.40-2.37$ \\
\hline Left & 310 & 100.0 & 1.95 & 0.19 & $1.47-2.40$ \\
\hline
\end{tabular}


Figure 1: Sonogram of longitudinal ultrasound scan showing where the three measurements of RPT at upper, middle and lower poles were made. This was the method of measurement of RPT by Roger et $\mathrm{al}^{5}$.

$[\mathrm{RPT}=\underline{1+2+3}]$

3

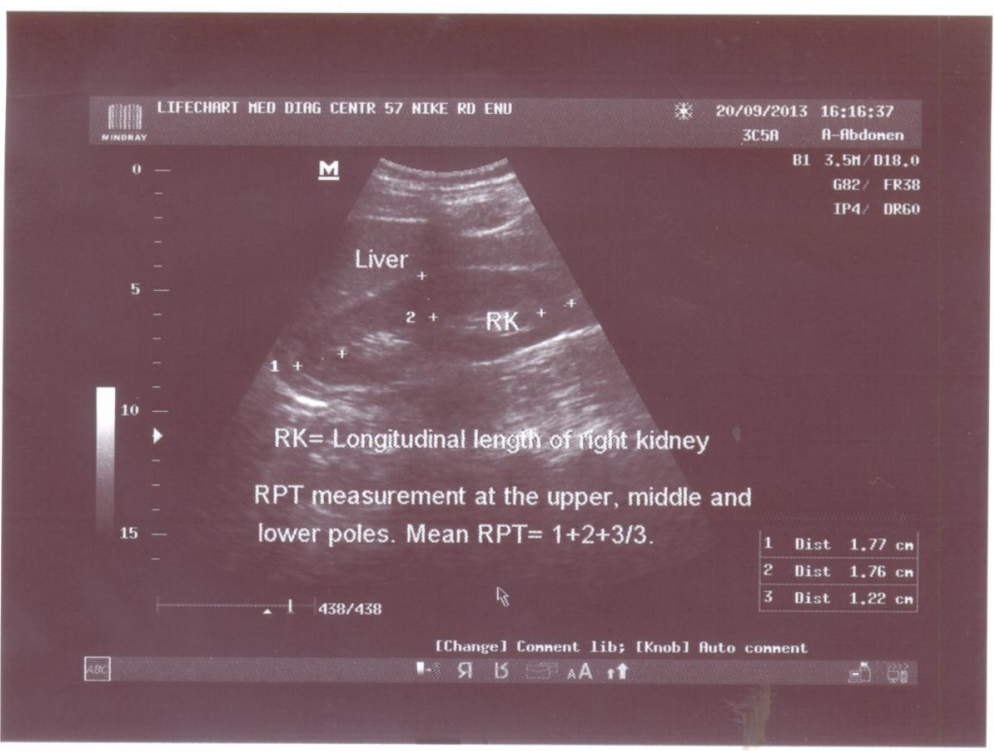

\section{Results}

The mean normal values for RPT were found to be 1.85

$\pm 0.20 \mathrm{~cm}$ (range $1.40-2.37 \mathrm{~cm}$ ) for the right kidney and $1.95 \pm 0.19 \mathrm{~cm}$ (range $1.47-2.40 \mathrm{~cm}$ ) for the left kidney (table 1).

Table 2. Age Distribution of Subjects and Corresponding mean RPT

\begin{tabular}{|l|l|l|l|l|}
\hline Age (Years) & Frequency & $\%$ & $\begin{array}{l}\text { Right mean RPT } \\
(\mathrm{cm})\end{array}$ & $\begin{array}{l}\text { Left mean RPT } \\
(\mathrm{cm})\end{array}$ \\
\hline $15-24$ & 56 & 18.0 & $1.92 \pm 0.19$ & $1.96 \pm 0.16$ \\
\hline $25-34$ & 113 & 36.5 & $1.97 \pm 0.22$ & $1.99 \pm 0.19$ \\
\hline $35-44$ & 59 & 19.0 & $1.94 \pm 0.18$ & $1.99 \pm 0.21$ \\
\hline $45-54$ & 31 & 10.0 & $1.86 \pm 0.23$ & $1.90 \pm 0.17$ \\
\hline $55-64$ & 34 & 11.0 & $1.75 \pm 0.16$ & $1.82 \pm 0.31$ \\
\hline $65-74$ & 14 & 4.5 & $1.74 \pm 0.30$ & $1.79 \pm 0.16$ \\
\hline $75-84$ & 3 & 1.0 & $1.68 \pm 0.20$ & $1.65 \pm 0.22$ \\
\hline Total & 310 & 100.0 & & \\
\hline
\end{tabular}

Mean age $=37.1$ years (range $18-80$ years)

Right Kidney: $2.08-0.0049$ Age $(\mathrm{r}=-0.81)$

Left Kidney: RPT $=2.13-0.0053$ Age $(r=-0.27)$ 


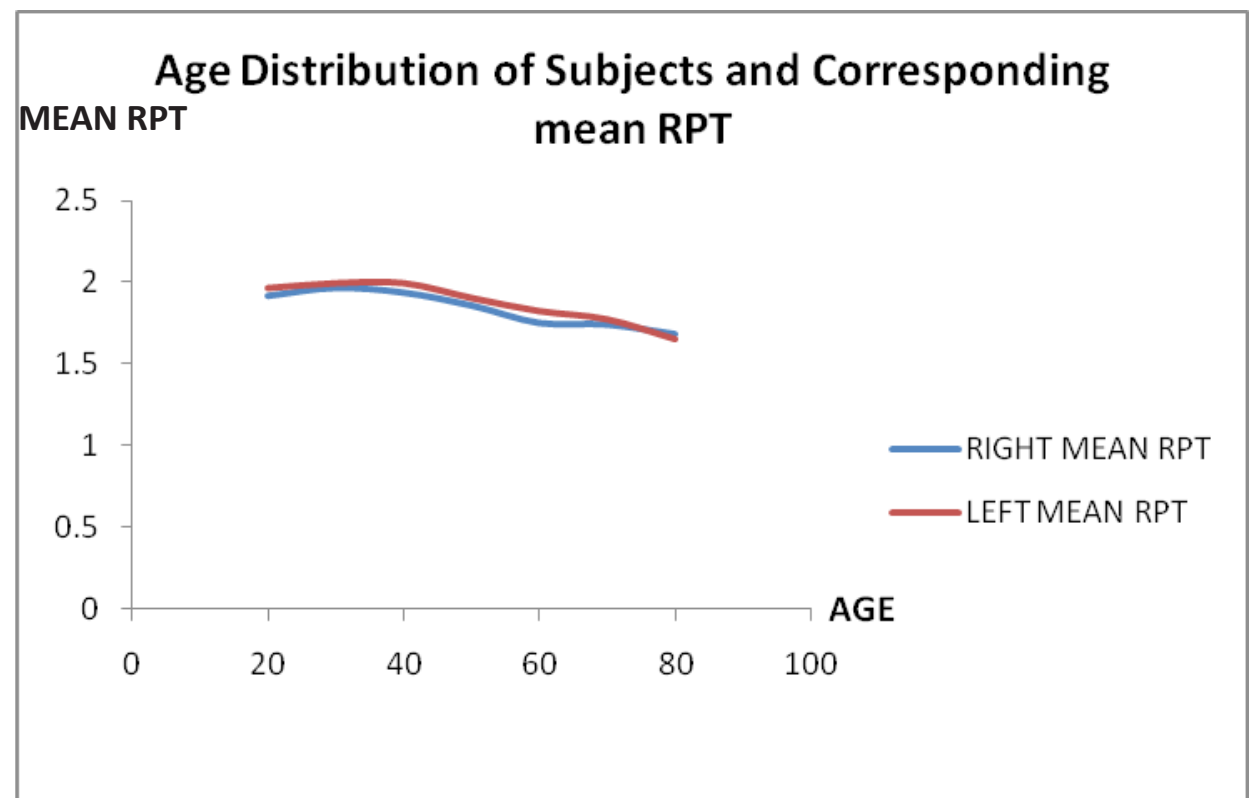

RPT showed significant negative correlation with age (table 2 and figure 2) but exhibited strong positive correlations with height (table 3 and figure 3), weight (table 4 and figure 4) and BMI (table 5 and figure 5). respectively.

Table 3. Height Distribution of Subjects \& Corresponding mean RPT

\begin{tabular}{|l|l|l|l|l|}
\hline Height $(\mathrm{cm})$ & Frequency & $\%$ & $\begin{array}{l}\text { Right mean RPT } \\
(\mathrm{cm})\end{array}$ & $\begin{array}{l}\text { Left mean RPT } \\
(\mathrm{cm})\end{array}$ \\
\hline $135-144$ & 4 & 1.3 & $1.98 \pm 0.23$ & $2.00 \pm 0.20$ \\
\hline $145-154$ & 63 & 20.3 & $1.86 \pm 0.12$ & $1.95 \pm 0.19$ \\
\hline $155-164$ & 133 & 42.9 & $1.90 \pm 0.18$ & $1.94 \pm 0.17$ \\
\hline $165-174$ & 83 & 26.8 & $1.90 \pm 0.22$ & $1.96 \pm 0.15$ \\
\hline $175-184$ & 25 & 8.1 & $1.98 \pm 0.16$ & $1.99 \pm 0.21$ \\
\hline $185-194$ & 2 & 0.6 & $2.17 \pm 0.23$ & $2.29 \pm 0.19$ \\
\hline Total & 310 & 100.0 & & \\
\hline
\end{tabular}

Right Kidney: RPT $=1.34+0.0038 \mathrm{HT}(\mathrm{r}=0.65)$

Left Kidney: RPT $=1.27+0.0045$ HT $(\mathrm{r}=0.67)$ 


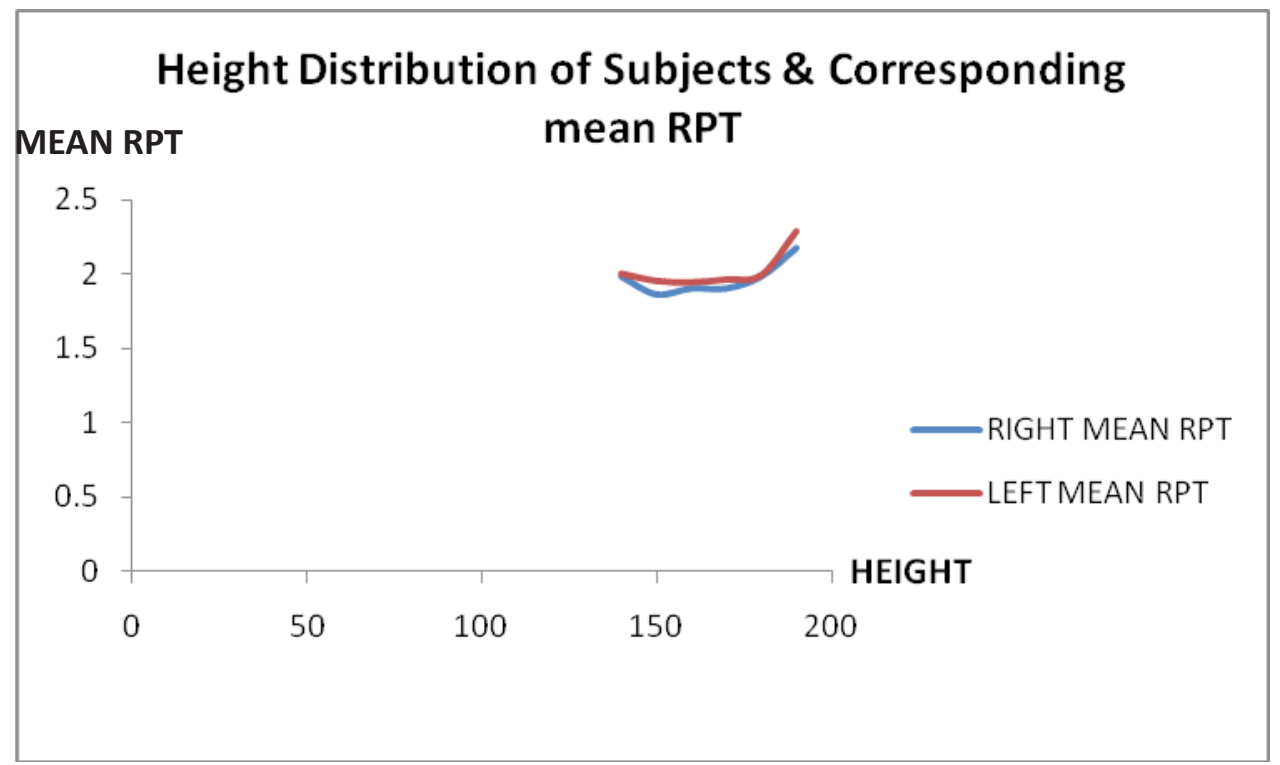

There were 135 males (43.5\%) and 175 females (56.5\%) in the adult population studied. The male mean RPT $(1.94 \pm 0.26 \mathrm{~cm})$ was not found to be statistically higher than the female mean RPT $(1.92 \pm 0.13 \mathrm{~cm})(\mathrm{p}>$ 0.05). The mean RPT of the left kidney was found to be statistically higher than the mean RPT of the right kidney $(p<0.05)$. There were statistically significant differences in the mean RPT of the study group and that of Caucasian and Pakistani populations compared with it $(\mathrm{p}<0.05)$.

Table 4. Weight Distribution of Subjects \& Corresponding mean RPT

\begin{tabular}{|l|l|l|l|l|}
\hline Weight & Frequency & $\%$ & $\begin{array}{l}\text { Right mean RPT } \\
(\mathrm{cm})\end{array}$ & $\begin{array}{l}\text { Left mean RPT } \\
(\mathrm{cm})\end{array}$ \\
\hline $45-54$ & 43 & 13.9 & $1.81 \pm 0.22$ & $1.84 \pm 0.19$ \\
\hline $55-64$ & 110 & 35.5 & $1.85 \pm 0.14$ & $1.89 \pm 0.21$ \\
\hline $65-74$ & 99 & 31.9 & $1.95 \pm 0.21$ & $1.99 \pm 0.17$ \\
\hline $75-84$ & 40 & 12.9 & $2.03 \pm 0.20$ & $2.08 \pm 0.18$ \\
\hline $85-94$ & 15 & 4.8 & $1.93 \pm 0.18$ & $1.95 \pm 0.19$ \\
\hline $95-104$ & 3 & 1.0 & $2.17 \pm 0.20$ & $2.20 \pm 0.17$ \\
\hline Total & 310 & 100.0 & & \\
\hline
\end{tabular}

Right Kidney: RPT $=1.51+0.006$ WT $(\mathrm{r}=0.90)$

Left Kidney: RPT $=1.54+0.006$ WT $(r=0.82)$ 
Figure 4: Scatter graph of weight versus mean RPT of both kidneys.

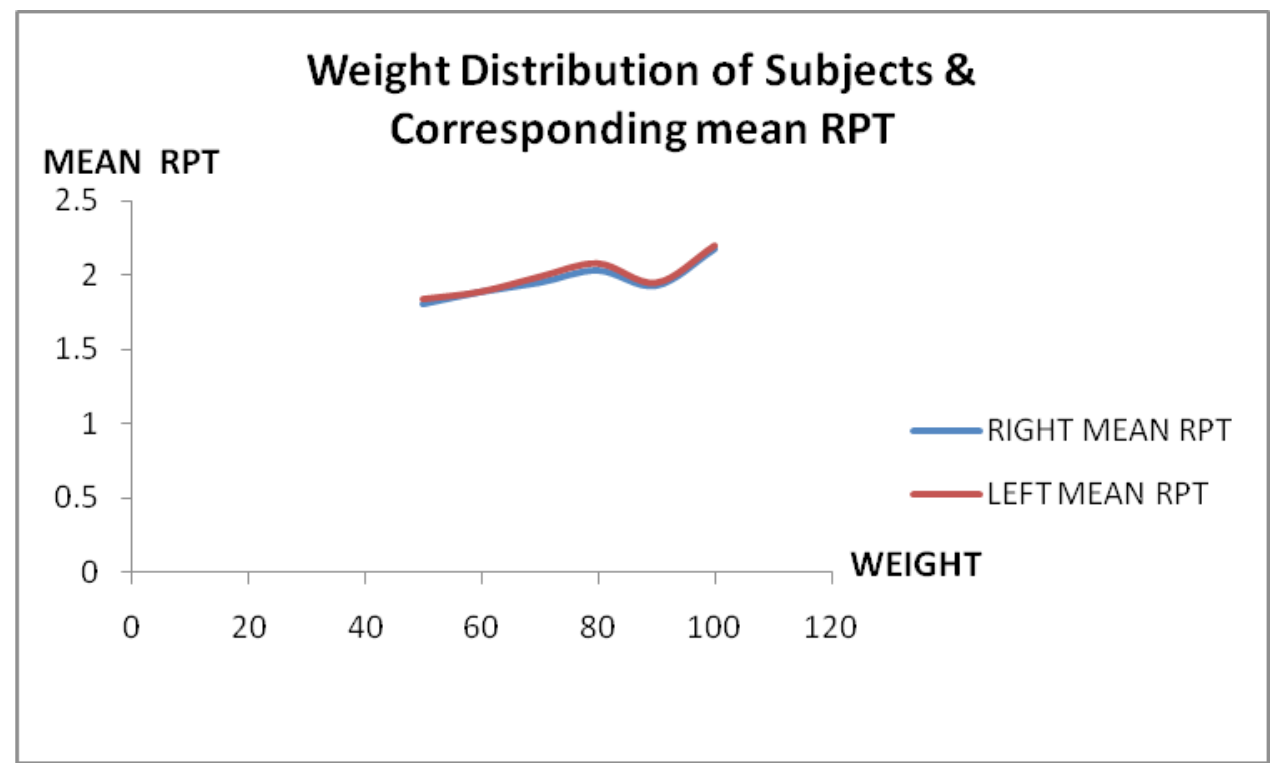

Table 5. BMI Distribution of Subjects and Corresponding mean RPT

\begin{tabular}{|l|l|l|l|l|}
\hline BMI $\left(\mathrm{Kg} / \mathrm{m}^{2}\right)$ & Frequency & $\%$ & $\begin{array}{l}\text { Right mean RPT } \\
(\mathrm{cm})\end{array}$ & $\begin{array}{l}\text { Left mean RPT } \\
(\mathrm{cm})\end{array}$ \\
\hline $14.0-16.9$ & 12 & 3.9 & $1.67 \pm 0.21$ & $1.63 \pm 0.18$ \\
\hline $17.0-19.9$ & 18 & 5.8 & $1.87 \pm 0.18$ & $1.89 \pm 0.17$ \\
\hline $20.0-22.9$ & 68 & 21.9 & $1.88 \pm 0.21$ & $1.90 \pm 0.21$ \\
\hline $23.0-25.9$ & 95 & 30.6 & $1.86 \pm 0.14$ & $1.91 \pm 0.19$ \\
\hline $26.0-28.9$ & 65 & 21.0 & $1.94 \pm 0.20$ & $1.98 \pm 0.18$ \\
\hline $29.0-31.9$ & 35 & 11.3 & $2.02 \pm 0.21$ & $1.99 \pm 0.19$ \\
\hline $32.0-34.9$ & 12 & 3.9 & $1.93 \pm 0.31$ & $1.98 \pm 0.21$ \\
\hline $35.0-37.9$ & 5 & 1.6 & $1.97 \pm 0.21$ & $2.05 \pm 0.13$ \\
\hline Total & 310 & 100.0 & & \\
\hline
\end{tabular}

Right Kidney: RPT $=1.47+0.017$ BMI $(r=0.84)$

Left Kidney: RPT $=1.54+0.015$ BMI $(r=0.90)$ 


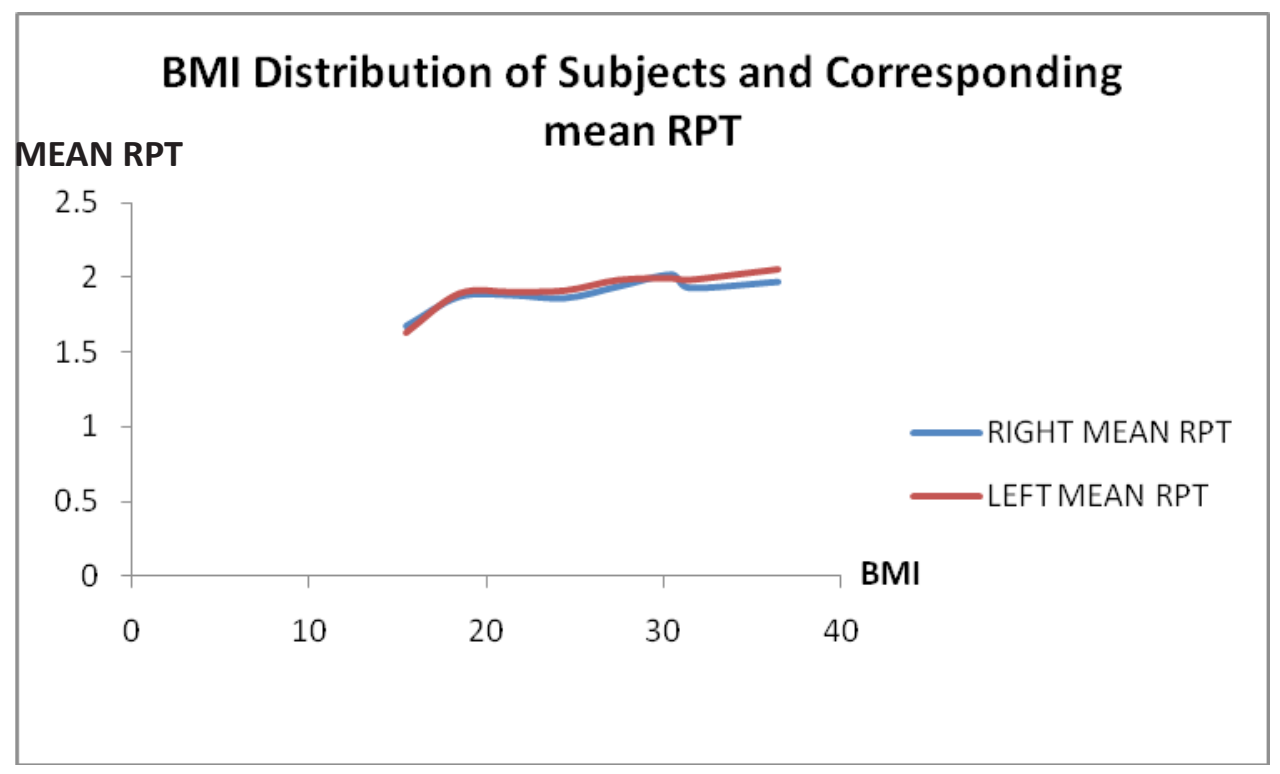

\section{Discussion}

Present study reveals that the average sonographic values for RPT among normal adults in Enugu, Southeast Nigeria were found to be $1.85 \pm 0.20 \mathrm{~cm}$ (range $=1.40$ $-2.37 \mathrm{~cm}$ ) for the right kidney and $1.95 \pm 0.19 \mathrm{~cm}$ (range $=1.47-2.40 \mathrm{~cm})$ for the left kidney. The combined mean RPT was found to be $1.94 \pm 0.20 \mathrm{~cm}$ (range $=$ $1.44-2.39 \mathrm{~cm})$ as against $1.89 \pm 0.36 \mathrm{~cm}$ (range $=$ $1.10-2.90 \mathrm{~cm})$ reported for a Caucasian population in UK. This implies that the lower limit of normal for RPT in our study group is $1.44 \mathrm{~cm}$. Values less than 1.44 $\mathrm{cm}$ indicate reduced RPT as against less than $1.10 \mathrm{~cm}$ reported for Caucasians ${ }^{5}$. The difference between mean RPT of this study and that of the Caucasian population based study was shown to be statistically significant $(p<0.05)$. The noted racial differences could be due to genetic and environmental variations as well as the relatively smaller sample size in a renal impaired population in the Caucasian study. In a relatively recent similar normal Pakistani adult population study ${ }^{13}$, the mean RPT values for the right and left kidneys were $1.44 \pm 0.29 \mathrm{~cm}$ (range $=0.8-2.9 \mathrm{~cm})$ and $1.51 \pm 0.31$ $\mathrm{cm}$ (range $=0.8-2.9 \mathrm{~cm})$ respectively. There was also a statistically significant difference in the mean RPT of the present study and that of the Pakistani population $(p<0.05)$. The noted smaller values of mean RPT of adult Pakistani population in comparison to adult Nigerian population from our study may be due to racial and geographical variations in renal parenchymal thickness. The larger population in the Pakistani based study (4,035 versus 310) might also have contributed to this significant difference. This range of RPT values from present study will serve as guide in renal size assessment for the selection of patients for biopsy and for evaluation of patients with chronic renal disease in our population.

The male mean RPT $(1.94 \pm 0.26 \mathrm{~cm})$ was not found to be statistically higher than the female mean RPT $(1.92 \pm 0.13 \mathrm{~cm})(p<0.05)$ especially if the BMI was taken into consideration. This absence of sex variation in RPT demonstrated by our study is in keeping with other related studies ${ }^{13,14}$. This implies that there is no need for special tables of RPT based on gender in our adult population.

This study found a significant negative correlation between RPT and age. Results from previous studies are generally consistent with this result ${ }^{5,14,15}$. This thinning of the renal parenchyma with age was attributed to the development of renal sinus lipomatosis with age ${ }^{16}$, and changes in the renal vasculature ${ }^{17}$. Renal parenchymal thickness in our study exhibited strong positive correlations with height, weight and BMI, with $\mathrm{r}$ values of $0.65 \& 0.67 ; 0.90 \& 0.82$ and $0.84 \& 0.90$ for the right and left kidneys respectively. These results are consistent with previous findings ${ }^{18,19}$. This is not surprising as there was a strong positive correlation between RL and $\mathrm{RPT}^{5,20}$ and between RL and height, weight and BMI ${ }^{18 \text {, }}$ ${ }^{19}$ in other related studies. This implies that sonographic assessment of RPT value can be better achieved with reference to these variables especially BMI in this population. 
In the present study, the mean RPT of the left kidney was found to be statistically higher than the mean RPT of the right kidney $(\mathrm{p}<0.05)$. This result agrees with previous studies in adult population ${ }^{13,18,21}$. However, one previous study done in children found no significant difference between the left and right kidneys ${ }^{19}$. This pattern in adults could be due to less space available to the right kidney for longitudinal growth because of the large liver on the right compared to relatively small spleen on the left side, especially as RPT has strong positive correlation with renal length ${ }^{5,20}$.

\section{Limitations of the study}

Larger subject numbers would have increased the reliability of the RPT nomograms. The interobserver and intraobserver variations in the measurements of RPT were not evaluated in this study. It is hoped that future studies would address these limitations.

\section{Conclusion}

Normal range for RPT measurements in relation to age and BMI are valuable when assessing kidney morphology on ultrasound. No differences in RPT exist between men and women if the BMI is taken into consideration. Empirically $1.44-2.39 \mathrm{~cm}$ represents a normal range of RPT measurement in adult Nigerians.

\section{Recommendations}

1. Present study considers $1.44-2.39 \mathrm{~cm}$ to represent normal range of RPT measurements in adult Southeast Nigerians. $1.44 \mathrm{~cm}$ RPT value is recommended as a critical value below which one could suggest a compromised RPT in the studied population.

2. RPT nomogram obtained with reference to age and BMI is another renal parameter that can be used with more confidence in the critical decision of whether or not to perform a renal biopsy among adult Nigerians.

3. Nomogram from this study is expected to provide a base line data for adult Nigerians that will probably be more accurate than using Caucasian and Asian based nomograms.

\section{Competing interests:}

None declared.

\section{Acknowledgement}

We thank Douglas Nwagbo and Chukwudi Ogbonna for their invaluable inputs in statistical analysis and data collections respectively.

\section{References}

1. Brown P. Ultrasound in Diffuse Renal Disease. British Medical Ultrasound Society Bulletin Nov. 2003; 11(4): 30-34.

2. Hricak H, Slovis TL, Callen PW, Romanski RN. Neonatal Kidneys: sonographic anatomic correlation. Radiology 1983; 147:669-702

3. Mostbeck GH, Kain R, Mallek R. Duplex Doppler sonography in renal parenchymal disease: Histopathologic correlation. Journal of Ultrasound Medicine, 1991; 10:189-194.

4. Page JE, Morgan SH, Eastwood JB, Smith SA, Webb DJ, Dilly SA, Chow J, Pottier A, Joseph AEA. Ultrasound findings in renal parenchymal disease. Comparison with histological appearances. Clinical Radiology 1994:867-870.

5. Roger SD, Beale AM, Cattel WR, Webb JAW. What is the value of measuring renal parenchymal thickness before renal biopsy? Clinical radiology. 1994; 49: 45-49.

6. Web JAW. The role of ultrasonography in the diagnosis of intrinsic renal disease. Clinical Radiology 1994; 49:589 - 591 .

7. Claesson I, Jacobsson B, Olsson T, Ringertz H. Assessment of renal parenchymal thickness in normal children. Acta Radiol Diagn (Stockh) 1981; 22: 305 314.

8. Prassopoulos P, Cavouras D. Renal parenchymal thickness in children measured by computed tomography. European Urology 1994; 25(1): 51-4.

9. Kadioglu A. Renal measurements, including length, parenchymal thickness and medullary pyramid thickness in healthy children. What are the ultrasound normative values? American Journal of Roentgenology 2010; 194 : $509-515$.

10. Ozoh JO, Okoye IJ, Umerah BC, Onuigbo MAC, Nwagbo DFE. Normal renal size in Nigerians. West African Journal of Radiology 1992; 2(1): 5-10.

11. Norton K and Olds I (eds). Anthropometrica. A textbook of body measurement for sports and health course. Sydney: University of New South Wales Press. 1996; Pp 25-73.

12. Nwabuokei PO. Fundamentals of statistics. Enugu: Koruna Books 1986; Pp241 - 242.

13. Mujahid R, Amina H, Imran KM. Ultrasonographic assessment of renal size and its correlation with body mass index in adults without known renal disease. J Ayub Med Coll Abbottabad 2011; 23(3): 64 - 68.

14. Faflia C, Prassopoulos P, Mkpakantaki A, Charoulakis N, Maris T, Chatzidakis A. Measurement of renal parenchymal thickness on ultrasonograms in relation to age, gender, body mass index and predicted clearance 
of creatinine. European congress of radiology 1999; Presentation 378.

15. Gourtsoyiannis N, Prassopoulos P, Cavouras P, Pantelids N. The thickness of renal parenchyma decrease with age; a CT study of 360 patients. American Journal of Roentgenology 1990; 155:541-544.

16. Mclachlan M, Wassermann P. Changes in size and distensibility of the ageing kidney. British Journal of Radiology 1984; 54:488-491.

17. Griffith G.J, Robison K.P, Cartwright G.O, Mclachlan M.S.F. Loss of renal tissues in the elderly. British Journal of Radiology 1976; 46:111-117.

18. Emmanian SA, Nielsen BM, Peterson FI, Ytte L. Kidney dimension at sonography: Correlation with age, sex and habitus in 665 adult volunteers. American Journal of Roentgenology 1993; 160: 83-86

19. Weisenbach J, Horvahth M, Jeges S, Adanovich K, Huszar T. Normal percentiles of the kidney size in children as measured by ultrasonography. Orv Hetil 2001; 142(2): 71-4.

20. Okoye IJ, Agwu KK, Eze CU. Relationship between sonographic renal length and renal parenchymal thickness in normal adult Southeast Nigerians. West African Journal of Medicine 2006; 25(1): 231 - 234.

21. Chou-YH, Chen-MT, Huang-CH. The correlation between ultrasound detected renal parenchymal thickness and isotope detected individual renal function. Kaohsiung Journal of Medical Science. 1997; Nov; 13 (11): 682-684 